Www.jmscr.igmpublication.org

Index Copernicus Value: 79.54

ISSN (e)-2347-176x ISSN (p) 2455-0450

crossrefDOI: https://dx.doi.org/10.18535/jmscr/v7i1.137

\title{
Study of Pap Smear Reporting in Asymptomatic women from a rural set up
}

\author{
Authors \\ Ranjana Deka, Usha Sarma
}

Gauhati Medical College

\begin{abstract}
Background: Cancer cervix is a leading cause of mortality and morbidity in developing countries like India most probably due to lack of proper screening facilities in the rural and suburban areas or due to the lack of awareness amongst the women. Cervical cancer is the fourth most common cancer in the world.

Developing countries accounted to about $80 \%$ of the global burden. This study was conducted to find out importance of Pap Smear Test in differentiating premalignant and malignant lesions in a rural set up.

Method: The study is carried out in a tertiary Care Hospital - Tezpur Medical College amongst asymptomatic women.

Results: The study was carried out in 160 No. of women. Out of those 160 cases we have studied, $96.3 \%$ are inflammatory, $3.7 \%$ are epithelial cell abnormality, $2.5 \%$ are HSIL, $0.61 \%$ squamous carcinoma and 0.61 are LSIL

Conclusion: This study shows that PAP smear examination is an important method for diagnosing cervical cancer.

Keyword: PAP smear, HSIL (High grade squamous intra epithelial lesion), LSIL (low grade squamous intra epithelial lesion), SCC (Squamous cell carcinoma).
\end{abstract}

\section{Introduction}

Cervical cancer is a malignant neoplasm arising from the cervix uteri. It is the most common cancer in developing countries and common in developed countries. In India cervical cancer is the second most common cancer amongst women ${ }^{[1]}$. Cervical cancer screening programme helps in detecting of Cervical Cancer at its early and precancer stage. The screening programme is based mainly on PAP Smear testing. The PAP Smear is a very low cost non-invasive and simple bed side technique and its interpretation is also quick for an expert cytologist ${ }^{[2]}$. The reporting of PAP smear is done according to the Bethasda system (2001). The early stages of cervical cancer can be completely asymptomatic. One of the most common symptoms of cervical cancer is abnormal vaginal bleeding (menorrhagia, dysmenorrhea), but in some cases, there may be no obvious symptom until the cancer has progressed to an advanced stage $^{[3]}$. There are two main types of cervical cancer: Squamous cell carcinoma (SCC) and Adenocarcinoma ${ }^{[3]}$

The progression of pre cancerous lesion to full blown cancer needs a long duration of time. Hence the pap smear study plays a vital role in detection of high risk women. In 1941, Papanicolaou developed the procedure of smearing and staining of PAP smear and till date it is a popular - procedure screening of cervical cancer ${ }^{[4]}$. Pap smear detects the morphological change occurring in cervical epithelial cells and 
accordingly categorized broadly as NILM (No malignant lesion nor malignancy) and ECA (Epithelial cell abnormality) ${ }^{[5]}$. The routine PAP Smear test also detects morphological change occurred due to HPV infection, which is a key factor for cervical carcinogenesis ${ }^{[5]}$

\section{Aims and Objective}

The study has been carried out in a rural medical facility in Northern Assam, India with the aims and objectives of -

1) To observe pattern of Cervical epithelial cell abnormality detected in asymptomatic women.

2) To find out the other associated factors like age and parity with incidence of cervical abnormality.

\section{Methodology}

A cross sectional study was carried out from 160 numbers of PAP Smear that were collected from married, non pregnant and asymptomaic women. The written consent was taken from each of the participants and the methodology was explained to them. Pregnant women and unmarried women are excluded from this study. The specimens were collected from the transformation zone of the uterine cervix. Three slides of each case were collected and all are labelled and stained with PAP stain and reported according to the Bethesda system 2001 ${ }^{[5]}$. Statistical analysis are carried out according to the requirement of the study.

\section{Results}

The following results are summarized from our study.

Table: 1 The table showing case distribution along with percentage and number

\begin{tabular}{|l|c|c|}
\hline Cytology Report & No. of Case & $\mathbf{\%}$ \\
\hline Inflammatory & 148 & $96.3 \%$ \\
\hline ASCUS & 6 & $3.7 \%$ \\
\hline LSIL & 1 & $0.6 \%$ \\
\hline HSIL & 4 & $2.5 \%$ \\
\hline SCC & 1 & $0.60 \%$ \\
\hline Total & 160 & $100 \%$ \\
\hline
\end{tabular}

Table 2: Relation of age with various nonneoplastic and neoplastic pathology of cervix

\begin{tabular}{|l|c|c|c|c|c|}
\hline PAP smear report & $\begin{array}{c}\mathbf{1 8 -} \\
\mathbf{3 0}\end{array}$ & $\begin{array}{c}\mathbf{3 1 -} \\
\mathbf{4 0}\end{array}$ & $\begin{array}{c}\mathbf{4 1 -} \\
\mathbf{5 0}\end{array}$ & $\mathbf{5 1 - 6 0}$ & Total \\
\hline Inflammatory & 0 & 5 & 46 & 97 & 148 \\
\hline ASCUS & 0 & 0 & 2 & 4 & 6 \\
\hline LSIL & 0 & 0 & 1 & 0 & 1 \\
\hline HSIL & 0 & 0 & 1 & 3 & 4 \\
\hline SCC & 0 & 0 & 1 & 0 & 1 \\
\hline Total & 0 & 5 & 51 & 104 & 160 \\
\hline
\end{tabular}

Table 3: Showing Parity wise Pap smear Report

\begin{tabular}{|l|c|c|c|c|c|}
\hline Pap Smear & NILM & \multicolumn{4}{|c|}{ Epithelial Cell Abnormality (7.5\%) } \\
\cline { 3 - 6 } Report & $(92.5 \%)$ & ASCUS & LSIL & HSIL & SCC \\
\hline Parity $=<2$ & 88 & 2 & 0 & 1 & 0 \\
\hline Parity $>2$ & 60 & 4 & 1 & 3 & 1 \\
\hline Total $\mathrm{n}=160$ & 148 & 6 & 1 & 4 & 1 \\
\hline
\end{tabular}

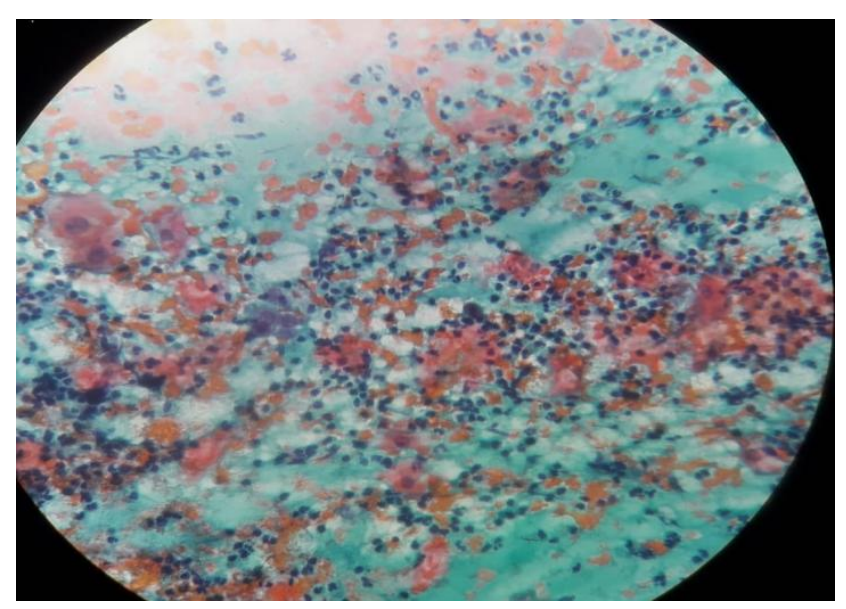

Figure : ASCUS

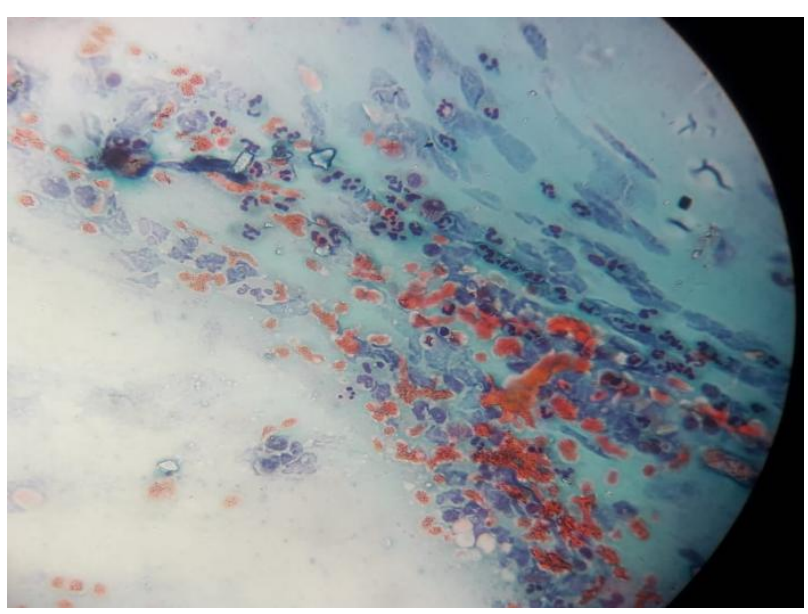

Figure : Inflammatory

\section{Discussion}

The study was carried out in 160 women from the age group18 years -60 years who were asymptomatic. They attended pap smear clinic for routine checkup. Present study revealed that NILM was $92.5 \%$ while it was $20.5 \%$ in a study 
by Nandini et al $^{[6]}$ and Western Maharastra. As the participants in the present study had no gynaecological symptoms, the NILM category is higher in comparision to others ${ }^{[7],[8]}$. Though the present study included asymptomatic women, ECA was detected in $7.5 \%$ of cases in screened women, a result comparable to ECA was $8.48 \%$ by Pusp ${ }^{[8]}$ et al, $11.95 \%$ and $12.60 \%$ by Sarma ${ }^{[9]}$ et al and Patel et al respectively. In spite of being asymptomatic, cytological abnormality has been noted in $7.5 \%$ of total pap smear evaluated comparable to the result found by Pusp et al ${ }^{[8],[9]}$. Hence it is advisable that pap smear testing should reach to each corners of the villages; health education regarding pap smear can help tremendously. All the women population after the start of sexual activity should undergo routine screening of their transformation zone of uterine cervix regularly. This helps in detecting the ECA at microscopic level. Those cases who are negative for malignancy in 3 consecutive report should be screened after 2-3 years. The American Cancer Society recommends that all women should begin cervical cancer screening after 3 years of beginning coitus. It is also recommended every 1-2 years, women who have crossed the age of 30 years and have had 3 consecutive normal Pap results may be screened after 2-3 years.

\section{Conclusion}

This study shows that PAP smear examination is an important method for diagnosing cervical cancer. It is widely accepted screening method. In countries like India with predominant rural population is having low socio-economic status, marriage at an early age and poor medical facility. It is a major challenge to formulate a screening program that is easily available, within existing resources, to a large section of society. It is also important to set clear and realistic long term goals. We can develop a cost effective screening method by training medical and paramedical staff at primary health centre level. PAP smear examination should begin at 30 years.
Funding: No funding sources

Conflict of interest: None declared

Acknowledgement: Dr. Mrs. Swapna Deuri

\section{References}

1. Ferlay J. GLOBOCAN 2002: cancer incidence, mortality and prevalence worldwide, version 2.0, Lyon, France: International Agency for Research on Cancer, 2004.

2. Dillman. edited by Oldham RK, Robert O. Principles of cancer biotherapy. 5th ed. Dordrecht: Springer; 2009:149.

3. Kumar V, Abbas AK, Fausto N, Mitchell RN. Robbins Basic Pathology. 8th ed. Saunders Elsevier; 2007:718-721.

4. Papanicolaou GN, Traut HT. The diagnostic value of vaginal smears in carcinoma of the uterus. Amer J Obstet Gynec 1941:42;193206.

5. Solomon D, Davey D, Kurman R, Moriarty A, O'Connor D, Prey M, et al., "The 2001 Bethesda System terminology for reporting results of cervical cytology". JAMA 2002; 287 : 2114-9.

6. Walboomers, J.M., Jacobs, M.V., et al. (1999) Human Papillomavirus Is a Necessary Cause of Invasive Cervical Cancer Worldwide. The Journal of Pathology, 189, 12-19.

7. Nandini B., Dinabandhu N., Aditya S. et.al. Cytological profile of PAP smear in a tertiary Care Hospital of West Bengal, India. IJ, P. December, 2016; vol.5: Issue 12, P.-4397

8. Pushp S. Minakshi S. A study on Cervical cancer screening using PAP smear Test and Clinical co-relation. Asia Pacific journal of oncology nursing. Vol. -5, Issue. 3, 2018. P337-341.

9. Sarma U, Mahata J., Talukdar K. Pattern of Abnormal Cervical Cytology in women attending a tertiary Hospital. Int. J. Sci. Res. Publ: 2012; 2.1-4. 